\title{
Sellado de catéteres centrales con medta versus heparina sódica
} al $\mathbf{1} \%$

\author{
Ma Concepción Pereira Feijoo, Andrés Pérez Blanco, Lidia Queija Martínez, Noelia Bretaña Vilanova, Sonia \\ María Cidón Fernández
}

Fundación Renal Î́nigo Álvarez de Toledo. Centro FRIAT Santa María. Orense

\section{Introducción:}

Los pacientes en programa de hemodiálisis son cada vez más añosos, aumentando las complicaciones en su acceso vascular. Los catéteres permanentes se presentan en algunos casos como el único acceso vascular posible, pero pueden presentar disfunciones y/o infecciones. Desde diciembre del 2011 en algunos pacientes (indicaciones específicas) se sellan con Medta (MINOCYCLINE-EDTA: 2mg/postHD, EDTA, sustancia quelante y anticoagulante que asociado con la minociclina tiene un amplio espectro antimicrobiano, sin manifestaciones de toxicidad). En nuestra unidad la permeabilidad de los catéteres es por lavado con arrastre con $10 \mathrm{ml}$ de suero fisiológico al 0,9\%, sellándolos con heparina al $1 \%$ en base a la longitud de las ramas del catéter.

\section{Objetivo:}

Evaluar la incidencia de trombosis e infecciones en relación con el sellado MEDTA en los pacientes de nuestra unidad comparándolo con sellado de heparina al $1 \%$.

\section{Material y métodos:}

La muestra de pacientes se corresponde con pacientes portadores de CVC (catéteres centrales) de nuestra unidad. Se estudian dos grupos, grupo control (pacientes sellados con heparina sódica al $1 \%$,), grupo estudio (pacientes seIlados con Medta). *Comunicación de nuevo protocolo a enfermeras de la unidad en relación al uso del MEDTA, cuando se pone en marcha el protocolo. * Uso exclusivo en pacientes con indicación (diabéticos, escasa asepsia personal, portadores de marcapasos y/o válvulas cardiacas, bacteriemias recurrentes y antecedentes de endocarditis) *Parámetros a estudio: Flujo sanguíneo eficaz: no inferior a $275 \mathrm{ml} / \mathrm{mn}$, infección local, bacteriemias, presión venosa elevada: mayores de 155 mmHg, coagulación cámara venosa, recambio de catéter por disfunción, recambio de catéter por infección: hemocultivos/antibioterapia utilizada, de alteplasa (no programada), cubrir checklist asociado a pacientes portadores de catéter, una valoración por cada sesión de HD.

\section{Resultados:}

Se incluyen 36 pacientes, 18 incluidos en protocolo MEDTA y 18 se sella el catéter con heparina sódica al $1 \%$. Se revisaron en total 150 sesiones de hemodiálisis realizadas en nuestro centro, que corresponden con las diálisis realizadas a estos pacientes en 2012. Se comprueba que la cumplimentación del Checklist por parte del personal de enfermería de la unidad es del $100 \%$. Los datos referentes a presión venosa, coagulación de cámara venosa, flujo sanguíneo eficaz fueron similares en ambos protocolos. En relación al flujo sanguíneo se registraron más casos de flujo inadecuado en el sellado con heparina, siendo necesario más veces invertir ramas o la utilización de alteplasa. Los datos de infección sistémica (uso de antibioterapia IV) fueron mayores en los pacientes con sellado de heparina, todas las infecciones fueron de orificio.

\section{Conclusiones:}

La valoración de los parámetros intradialíticos fue similar en ambos sellados, no existiendo ningún ingreso hospitalario por disfunción del catéter. En relación 
al flujo efectivo de diálisis se ha detectado que en el caso de heparina sódica al $1 \%$ hubo más dificultad para conseguirlo. Aunque la muestra de pacientes no es demasiado grande, esperamos poder ampliar el estudio con resultados más significativos a lo largo de los próximos años utilizando dicho producto.La utilización del Medta para el sellado de CVC ha sido efectiva para disminuir las infecciones. Implicación del personal de enfermería en el protocolo $100 \%$.

\section{Referencias Bibliográficas}

1. Lynn. Hadaway: Las mejores intervenciones de enfermería para mantener la vía central libre de in fección: Nursing 2007, Volumen 25, número 5.

2. Vifan Xue.Central venous access device (CVAD): Maintenance jbi database of evidence summaries 2010.
3. 3. Ministerio de Sanidad y Política Social.Proyecto Bacteriemia Zero.Material Didáctico.Ministerio de Sanidad y Política Social. Plan de Calidad del SNS de 2009.

4. Sociedad de Enfermería intravenosa(http:// ww.insl.org).

5. Borra Moltó C.Accesos Vasculares y Eficacia Dialítica.Comunicacciones del XXXI Congreso de la Sedén.Cordoba 2006.hospal 2006.página 115.

6. Polaschegg HD, Sodemannk, Feldmerb: Aumento de la permeabilidad, seguridad y eficacia en el coste de los catéteres.EDTNA/ERCA Journal 2002;XXVIII: 29-33.

7. R Jofré, J Ma López Gómez, J.Luño, R.Pérez García, Rodríguez Benítez.Tratado de Hemodiálisis, segunda edición actualizada, 2006. 